\title{
Maze Learning by Adult Rats after Inhibition of Neuronal Multiplication in Utero
}

\author{
B. P. F. ADLARD AND JOHN DOBBING(28) \\ Department.of Child Health, University of Manchester, \\ Manchester, United Kingdom
}

\section{Extract}

Rats whose mothers received hydroxyurea ( $\mathrm{HU}, 1$ or $2 \mathrm{~g} / \mathrm{kg}$ ) at 14 days of gestation had a $30 \%$ deficit in both brain and body weight at birth, when compared with controls. Number of brain cells at birth (mainly neurons) was reduced by $33-34 \%$. A severe reduction in postnatal whole brain growth (31-33\% in adulthood) was observed, but the cerebellum was relatively spared. In the Hebb-Williams maze text in adulthood HU animals made $28 \%$ more errors than controls over 12 problems. The differences were much more marked on certain problems and for HU animals with particularly small brains. In a T-maze spatial discrimination test in adulthood HU rats learned the initial response normally but, when required to reverse this response, showed a significant tendency to make more perseverative errors than controls.

\section{Speculation}

Rats exposed to an inhibitor of cell division at the beginning of the major period of brain neurogenesis showed deficits in learning ability in adulthood. The large number of mentally retarded human children whose handicap is without known etiology may have suffered a similar early loss of neurons, and if so, this preparation could provide a useful animal model.

The period of neuronal multiplication in the mammalian central nervous system is relatively short and, except in the cerebellum and hippocampus (2), occurs well before the major phase of brain growth and physiologic development. For example, in man neuron formation is largely complete by 20 weeks of gestation (8), whereas rat brain neurogenesis, as assessed by accumulation of DNA, occurs between approximately 13 and 20 days of gestation (5).

It has been suggested (6) that in man certain forms of mental retardation, involving microcephaly, but the etiology of which is unknown, might result from an interference with neuronal multiplication during the second trimester by as yet unspecified agents. With this hypothesis in mind we have examined the maze learning ability of adult rats whose mothers received a specific inhibitor of DNA synthesis (HU) on the 14th day of gestation.

\section{METHODS}

\section{HYDROXYUREA TREATMENT}

Maternal rats, of a black and white hooded strain, had successfully reared $1-3$ litters. The day of mating (day 0 ) was determined by examination of vaginal smears for sperm. On day 14 of gestation rats were injected intraperitoneally with either saline $(10 \mathrm{ml} / \mathrm{kg}$ body weight) of HU (26) (1 or $2 \mathrm{~g} / \mathrm{kg}$ body weight) suspended in a corresponding volume of saline. On the day of birth ( 21 or 22 days of gestational age), litters were reduced to eight animals (four males, four females) and fostered to a saline-treated mother giving birth on the same day. Both control (saline-treated) and $\mathrm{HU}$ animals were so fostered. A number of excess animals from each litter was killed for estimation of brain DNA (25). At 25 days of age half of the animals in each litter were killed and the whole brain and cerebellum was dissected out and weighed. The remaining animals (up to two males, two females) were weaned and subsequently housed two per cage.

\section{HEBB-WILLIAMS MAZE}

Rats aged 13-15 weeks were tested in a Hebb-Williams maze (20). The light cycle was $12 \mathrm{hr}$ of red, beginning at 07.00 $\mathrm{hr}$, and $12 \mathrm{hr}$ of white. Animals were kept at about $80 \%$ of their predicted free-feeding weight throughout the period of testing, and were run for a food reward, in two sessions/day, during the red phase of their light cycle.

\section{T-MAZE}

Rats aged 20-23 weeks were tested in a water T-maze as described previously for guinea pigs (1). The light cycle was 12 $\mathrm{hr}$ of red, beginning at $12.00 \mathrm{hr}$, and $12 \mathrm{hr}$ of white. Rats were required to swim and make a left-right discrimination in order to escape. Escape was possible from one arm only. An entry into a blocked arm, or re-entry into the starting arm, constituted an error. Testing was carried out at 09.00-12.00 hr. Each animal was given 10, trials/day for 6 days. Animals from these two groups were tested in random order which was consistent from day to day. On days 5 and 6 the escape route was reversed and the ability to learn the reversal was thus examined.

\section{STATISTICS}

Mean values were compared using the Student $t$ test, except where otherwise indicated.

\section{RESULTS}

\section{GROWTH AND DEVELOPMENT}

Hydroxyurea treatment had no obvious ill effects on the pregnant rats and weight gain to parturition was normal. There was no effect on the number of liveborn offspring when compared with controls. A high proportion of newborn offspring of HU-treated mothers had a kinked tail (21), but there were no other obvious external malformations. HU at 2 
$\mathrm{g} / \mathrm{kg}$ (but not at $1 \mathrm{~g} / \mathrm{kg}$ ) resulted in a high neonatal mortality. The complete litters of 3 out of 7 mothers receiving HU $2 \mathrm{~g} / \mathrm{kg}$ died in the first $48 \mathrm{hr}$ of life. In contrast, neonatal mortality in the HU $1 \mathrm{~g} / \mathrm{kg}$ group was negligible. The postnatal mortality rate (48 $\mathrm{hr}$ to adulthood) of all $\mathrm{HU}$ animals was small and not significantly different from controls.

Hydroxyurea treatment markedly affected fetal growth (Table 1). The mean body weight of those animals killed at birth in each group (Table 1) was similar to mean birth weight of all of the rats born in that group. The brain weight deficit was comparable with that of the body, and was associated with a comparable deficit in numbers of cells (total DNA). There were no differences in any of these parameters between the two HU dosage groups.

There were no significant sex differences in growth to 25 postnatal days, and results have therefore been pooled (Table 2). Hydroxyurea treatment significantly affected body size at 25 days, but the effect on brain weight was greater, and hence the brain to body ratio was significantly lower than in controls. Cerebellar growth was retarded significantly less than that of the whole brain.

Body and brain weights in adult animals (Table 2) were measured in those killed after 3 weeks of refeeding after Hebb-Williams maze testing. Males of the HU group showed an equal percentage of deficit in body and brain weight. In contrast, females showed a smaller effect on ultimate body size and a significantly reduced brain to body ratio when compared with controls.

\section{PIGMENTATION}

Prenatal HU had a striking effect on the extent of coat color in that pigment failed to appear on certain parts of the body. In Figure 1 a typical control is compared with a typical rat whose mother received $\mathrm{HU}(1 \mathrm{~g} / \mathrm{kg})$. Characteristically, HU animals showed relatively normal head pigmentation but a great reduction in the extent of pigment on the back. Often the back was entirely white, a phenomenon not normally occurring in the colony.

\section{HEBB-WILLIAMS MAZE}

Total errors and total running times for the 12 problems of the Hebb-Williams maze are given in Table 3. Prenatal treatment with $\mathrm{HU}$ significantly increased the number of errors made by either sex, but did not affect the running time. Total errors were not affected by the dose of $\mathrm{HU}(1$ or $2 \mathrm{~g} / \mathrm{kg}$ ).

Hydroxyurea rats with a brain weight greater than $1,250 \mathrm{mg}$ ( $\mathrm{n}=4,2$ males, 2 females) made $177 \pm 26$ (mean \pm SD) errors, significantly $(P<0.01)$ less than those with a brain weight below $1,250 \mathrm{mg}(\mathrm{n}=13,5$ males, 8 females). The high brain weight HU group did not differ from controls in total errors.

\section{T-MAZE}

On days 1-4 (Fig. 2), during which the escape route (left or right) was constant, there were no significant effects of treatment on performance in the T-maze (for errors $F=0.60$, df $1 / 80$; and for errorless runs $F=1.72$, df $1 / 80$ ).

On day 5, when the escape route was reversed, HU rats made significantly fewer errorless runs (i.e., performed worse) than controls $(P<0.05)$. Despite this difference, HU rats did not make more errors than controls on day 5. This apparent paradox resulted from a difference between the two groups in distribution of errors over the 10 trials of day 5. On trial 1 (Fig. 3), when animals first encountered a blocked arm which had previously provided an escape route, controls made almost 3 times as many errors as HU rats $(P<0.01)$. However, on trial 2, controls showed an improvement $(P<0.001$, paired comparisons $t$ test) to almost perfect performance whereas $\mathrm{HU}$ animals did not improve significantly between trials 1 and 2 (Fig. 3).

In contrast to the relative performance on trial 1, over trials $2-10$ (day 5), HU rats made $3.55 \pm 0.30$ (mean \pm SEM) errors, 5 times as many as controls, who made $0.72 \pm 0.07$ errors $(F=14.61$, df $1 / 180, P<0.001)$. Of the total errors made on day $5 \mathrm{HU}$ rats made $53 \%$ on trials $2-10$ whereas the corresponding value for controls was only $15 \%(P<0.01)$.

\section{DISCUSSION}

Hydroxyurea is an inhibitor of DNA synthesis $(13,23)$, but is without effect on protein or RNA metabolism (24). It is therefore potentially useful experimentally as a specific antimitotic agent in tissues undergoing rapid cell division. The period of action of $\mathrm{HU}$ is confined to the S (DNA-synthesising) phase of the cell cycle (19) and the mechanism probably involves inhibition of ribonucleotide reductase (ribonucleoside diphosphate reductase, EC. 1.17.4.1) $(11,18,23)$, an enzyme involved in the biosynthesis of deoxyribonucleotides (immediate precursors of DNA).

In the present study $\mathrm{HU}$ was given in pregnancy at the time of onset of rapid neuronal multiplication in the rat brain (5). In agreement with a previous report (16), the total number of brain cells at birth (probably mainly neurons) was severely reduced compared with controls. This difference may have resulted specifically from a blockade of the early phase of neuronal multiplication, since $\mathrm{HU}$ in the doses used disappears from fetal rat tissues within about $48 \mathrm{hr}$ (21).

Hydroxyurea treatment resulted in microcephaly (reduced brain to body ratio) at 25 days of age, before the major period of body growth. Adult females also showed microcephaly, but adult males showed equally severe effects on both brain and body size. The size of the cerebellum at 25 days was less affected than the remainder of the brain by prenatal HU, presumably reflecting the fact that cerebellar neurogenesis is largely a postnatal event in the rat (2). With respect to possible mechanisms involved in mental retardation, it is of interest that the most common neuropathologic finding in the retarded is of a microcephaly associated with relative sparing of the cerebellum (4).

Apart from the severe reduction in adult brain weight the detailed neuroanatomic effects of HU treatment are unknown

Table 1. Body and brain weights at birth after hydroxyurea (HU) treatment on day 14 of gestation ${ }^{1}$

\begin{tabular}{lccc}
\hline & Control & HU, $1 \mathrm{~g} / \mathrm{kg}(\%)$ & $\mathrm{HU}, 2 \mathrm{~g} / \mathrm{kg}(\%)$ \\
\hline $\mathrm{N}$ & 20 & 15 & 12 \\
Body wt $(\mathrm{g})$ & $5.78 \pm 0.57$ & $4.20 \pm 0.47^{2}(-27)^{3}$ & $3.95 \pm 0.44^{2}(-32)$ \\
Brain wt $(\mathrm{mg})$ & $234 \pm 23$ & $169 \pm 15^{2}(-28)$ & $164 \pm 18^{2}(-30)$ \\
Brain DNA & $1.41 \pm 0.19$ & $0.93 \pm 0.15^{2}(-34)$ & $0.95 \pm 0.11^{2}(-33)$ \\
( $\mu$ mol DNA-P) & & & $4.16 \pm 0.22$ \\
Brain to body ratio $(\%)$ & $4.05 \pm 0.21$ & $4.05 \pm 0.23$ & 4 \\
\hline
\end{tabular}

\footnotetext{
${ }^{1}$ Results (mean \pm SD) are based on animals from the following numbers of litters: control, $15 ; \mathrm{HU}(1 \mathrm{~g} / \mathrm{kg}), 7 ; \mathrm{HU}(2 \mathrm{~g} / \mathrm{kg}), 7$.

${ }^{2} P<0.001$, compared with controls.

${ }^{3}$ Figures in parentheses represent percentage deficits compared with controls.
} 
Table 2. Body and brain weights at weaning and in adulthood ${ }^{1}$

\begin{tabular}{lcc}
\hline & Control & HU (\%) \\
\hline Male + female, 25 days & & 19 \\
$\mathrm{~N}$ & 25 & $44.5 \pm 4.2^{2}(-20)^{3}$ \\
Body wt (g) & $55.6 \pm 11.0$ & $963 \pm 42^{2}(-31)^{3}$ \\
Brain wt (m) & $1,390 \pm 91$ & $153 \pm 16^{2}(-19)^{3}$ \\
Cerebellum wt (mg) & $188 \pm 17$ & $2.17 \pm 0.14^{2}$ \\
Brain to body ratio (\%) & $2.60 \pm 0.51$ & $15.9 \pm 1.2^{2}$ \\
Cerebellum to whole & $13.4 \pm 0.7$ & \\
brain ratio (\%) & & $7 \cdot$ \\
Male, 18 wk & 12 & $250 \pm 30^{2}(-32)^{3}$ \\
$\mathrm{~N}$ & $368 \pm 38$ & $1,230 \pm 87^{2}(-33)^{3}$ \\
Body wt (g) & $1,840 \pm 66$ & \\
Brain wt (mg) & & $10.495 \pm 0.039$ \\
Brain to body ratio (\%) & $0.502 \pm 0.037$ & $188 \pm 20^{2}(-15)^{3}$ \\
Female, 18 wk & 12 & $1,160 \pm 103^{2}(-31)^{3}$ \\
$\mathrm{~N}$ & $223 \pm 22$ & $0.619 \pm 0.048^{2}$ \\
Body wt (g) & $1,670 \pm 66$ & \\
Brain wt (mg) & $0.757 \pm 0.063$ & \\
Brain to body ratio (\%) & & \\
\hline
\end{tabular}

${ }^{1}$ Results (mean \pm SD) are based on animals from the following numbers of litters: control, 15; hydroxyurea (HU) $(1 \mathrm{~g} / \mathrm{kg}), 7$; HU $(2 \mathrm{~g} / \mathrm{kg})$, 4. Results for $\mathrm{HU}$ animals at the two different doses were pooled.

$2<0.002$, compared with controls.

${ }^{3}$ Figures in parentheses represent percentage deficits compared with controls.

but, by analogy with the effects of prenatal X-irradiation (14, $15)$, these might involve disturbances in brain cellular architecture in addition to effects on gross organ size. The influence of $\mathrm{HU}$ on pigment cell formation has not been noted previously, inasmuch as other workers have used albino rats. Rat melanoblasts migrate from the neural crest to cover the whole body during the period of 15-20 days of gestation (22). It seems that $\mathrm{HU}$ at 14 days interferes with the formation and/or migration of cells to the back but not to the head (Fig. 1).

There could be analogies between the effects of HU on pigment cells and its possible effects on those neuroblasts which undergo migration from the periventricular areas to the cerebrel cortex. Detailed histologic studies will be required to answer this question. It is of interest that brains of the mentally retarded commonly show evidence (4) of abnormal gyral patterning (microgyria, pachygyria, etc.), probably resulting from disturbances of neuroblast migration. It might be of value to investigate the effects of $\mathrm{HU}$ in a species with a convoluted brain.

There is a striking contrast between the physical effects of $\mathrm{HU}$ reported here and those found in nutritional growth retardation during the fetal and suckling periods (9). In particular, the brain to body ratio is raised in undernourished rats (7), while the cerebellum is differentially affected, not spared. It is notable that microcephaly is much more severe when the number of neurons is reduced than when glia are missing, even though glia outnumber neurons heavily in normal brains. Perhaps the pattern of neuronal development strongly dominates the subsequent development of the brain.

A previous study (3) has suggested that prenatal $\mathrm{HU}$ affects learning ability in adulthood.

In the present work HU treatment resulted in a relatively severe impairment in Hebb-Williams maze performances. Since this test involves food deprivation, results might have been confounded by motivational differences. Hydroxyurea treatment did not, however, affect maze running time which would be expected to be dependent on drive state.

Deficits in discrimination learning in adulthood have been found after prenatal X-irradiation in rats (12) and prenatal heat stress in guinea pigs $(10,17)$. Both of these treatments, when applied at the time of major neurogenesis, result in a severe impairment in brain growth, and are therefore, in certain respects, analagous to $\mathrm{HU}$ treatment. In the $\mathrm{T}$-maze test $\mathrm{HU}$ rats showed normal learning of the initial response (days 1-4), but an abnormality on reversal (day 5). Specifically, HU animals escaped after fewer errors than controls on the first trial, but on subsequent trials made more errors than controls, the latter showing almost perfect performance. Thus, on a reversal learning task, HU treatment increased the number of "perseverative" errors.

It should be stressed that the effects of HU on brain growth and behavior need not necessarily have resulted directly from a

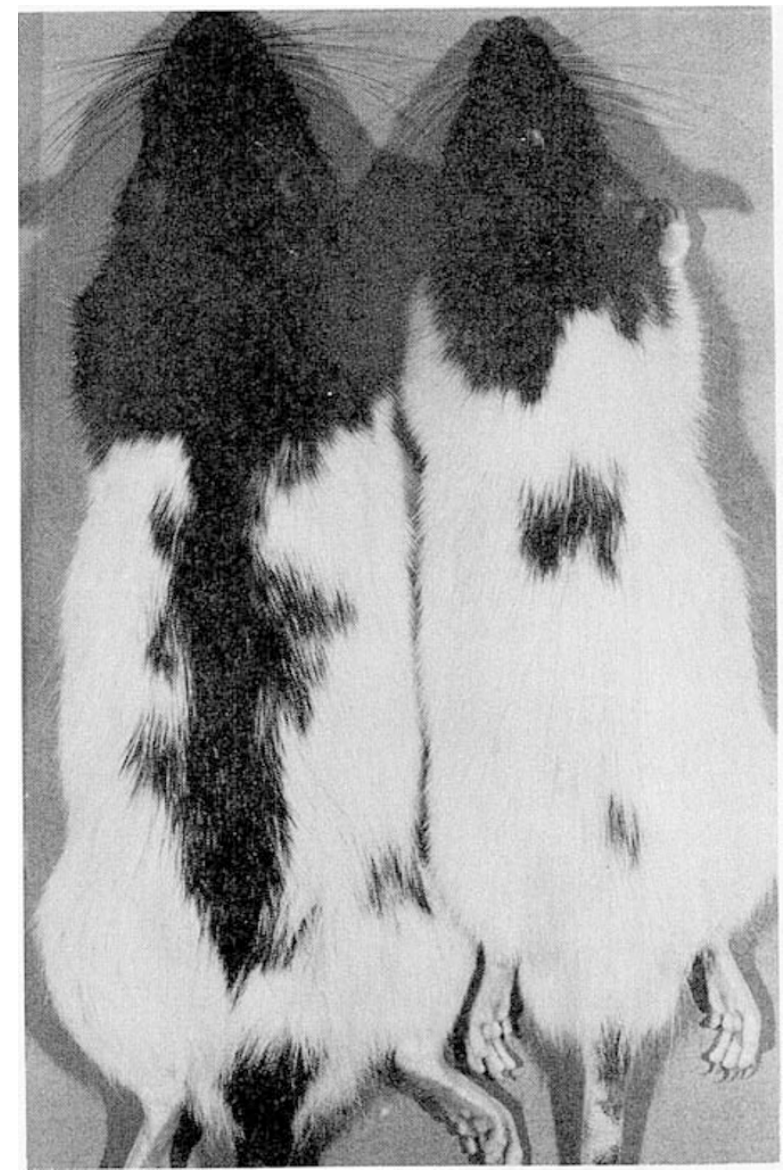

Fig. 1. Reduced pigmentation after hydroxyurea treatment. A typical control 23-week-old rat (left) is compared with a typical animal (right) whose mother received hydroxyurea $(1 \mathrm{~g} / \mathrm{kg})$ at 14 days of gestation. The marked difference in body size is also apparent.

Table 3. Hebb-Williams maze performance (totals for 12 problems 1

\begin{tabular}{lccl}
\hline \multicolumn{1}{c}{ Sex } & Control & HU & $P$ \\
\hline Errors & & & \\
$\delta$ & $164 \pm 25(12)$ & $202 \pm 33(7)$ & $<0.02$ \\
$\$$ & $170 \pm 22(12)$ & $223 \pm 35(10)$ & $<0.001$ \\
$\delta+q$ & $167 \pm 23(24)$ & $214 \pm 35(17)$ & $<0.001$ \\
Time (sec) & & & \\
$\square$ & $967 \pm 234(12)$ & $1,133 \pm 295(7)$ & n.s. \\
$\$$ & $878 \pm 312(12)$ & $1,034 \pm 571(10)$ & n.s. \\
$\delta+q$ & $922 \pm 274(24)$ & $1,075 \pm 467(17)$ & n.s. \\
\hline
\end{tabular}

${ }^{1}$ Results (mean $\pm \mathrm{SD}$ ) are based on animals (numbers indicated in parentheses) from the following numbers of litters: control, 15; hydroxyurea (HU) $(1 \mathrm{~g} / \mathrm{kg}), 7 ; \mathrm{HU}(2 \mathrm{~g} / \mathrm{kg}), 3$. Of $17 \mathrm{HU}$ rats, 11 were in the $1 \mathrm{~g} / \mathrm{kg}$ group and 6 were in the $2 \mathrm{~g} / \mathrm{kg}$ group. $n$.s.: Not significant. 


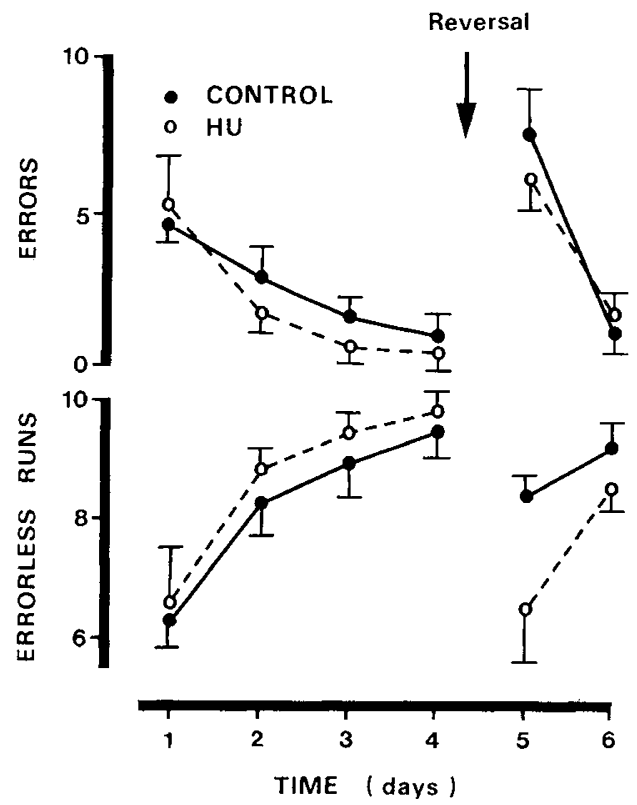

Fig. 2. T-maze performance at 20-23 weeks of age by control rats and those whose mothers received hydroxyurea $(H U)(1 \mathrm{~g} / \mathrm{kg})$ at 14 days of gestation. Each result is the mean $( \pm$ SEM) of 11 rats (five males, six females) from six litters. For statistics, see T-Maze under Results.

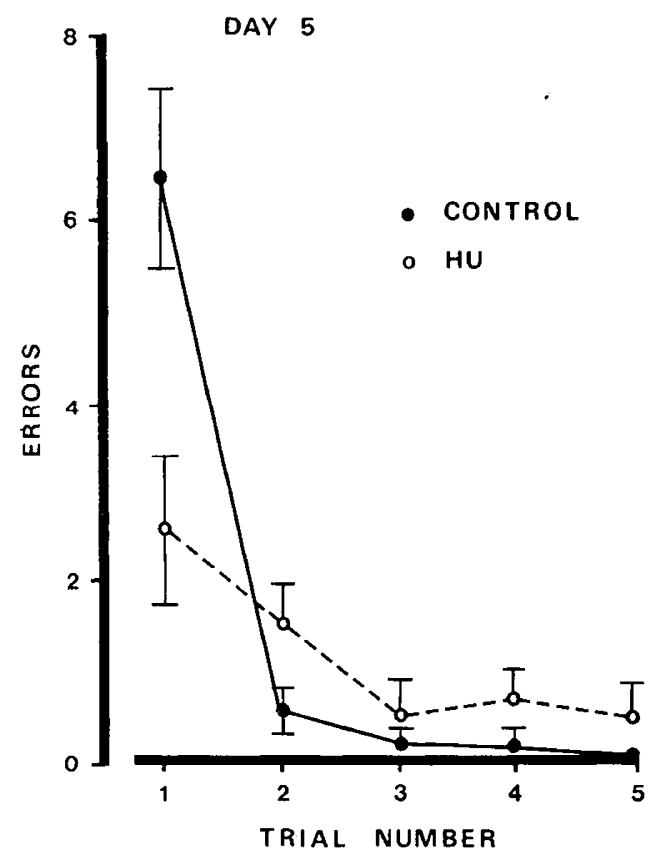

Fig. 3. T-maze errors on trials 1-5 of day 5. For other details, see Fig. 2. For statistics, see T-Maze under Results.

deficit in numbers of neurons. Since $\mathrm{HU}$ affects all tissues showing rapid cell division, possible secondary (e.g., endocrine) influences on brain development might also be important and will require investigation.

\section{SUMMARY}

Pregnant rats were treated with an antimitotic agent, HU (1 or $2 \mathrm{~g} / \mathrm{kg}$ ), at 14 days of gestation. Hydroxyurea offspring subsequently showed a severe retardation of brain growth. At birth, at 25 days of age, and in adulthood the brain weight deficit was at least as great as the reduction in body weight. In adulthood HU rats showed impaired performance in two tests of learning ability.

\section{REFERENCES AND NOTES}

1. Adlard, B. P. F., Moon, S., and Smart, J. L.: Discrimination learning in ascorbic acid-deficient guinea pigs. Nature, 247: 398 (1974).

2. Altman, J.: DNA metabolism and cell proliferation. In: A. Lajtha: Handbook of Neurochemistry, Vol. 2, p. 137 (Plenum Press, New York, 1969).

3. Butcher, R. E., Scott, W. J., Kazmaier, K., and Ritter, E. J.: Postnatal effects in rats of prenatal treatment with hydroxyurea. Teratology, 7: 161 (1973).

4. Crome, L., and Stern, J.: Pathology of Mental Retardation, p. 121 (Churchill-Livingstone, London, 1972).

5. Croskerry, P. G., Smith, G. K., Shepard, B. J., and Freeman, K. B.: Perinatal brain DNA in the normal and growth-hormone treated rat. Brain Res., 52: 413 (1973).

6. Dobbing, J.: The later development of the brain and its vulnerability. In: J. A. Davis and J. Dobbing: Scientific Foundations of Paediatrics, p. 565 (Heinemann, London, 1974).

7. Dobbing, J., and Sands, J.: Vulnerability of developing brain. IX. The effect of nutritional growth retardation on the timing of the brain growth spurt. Biol. Neonate, 19: 363 (1971).

8. Dobbing, J., and Sands, J.: Quantitative growth and development of human brain. Arch. Dis. Childhood, 48: 757 (1973).

9. Dobbing, J., and Smart, J. L.: Vulnerability of developing brain and behavior. Brit. Med. Bull., 30: 164 (1974).

10. Edwards, M. J., Lyle, J. G., and Penny, R. H. C.: Prenatal retardation of brain growth by hyperthermia and the learning capacity of mature guinea pigs. Develop. Psychobiol., in press.

11. Frenkel, E. P., Skinner, W. W., and Smiley, J. D.: Studies on a metabolic defect induced by hydroxyurea. Cancer Chemother. Rep., 40: 19 (1964).

12. Furchgott, E., Jones, J. R., Tacker, R. S., and Deagle, J.: Aversive conditioning in prenatally X-irradiated rats. Physiol. Behav., S: $571(1970)$.

13. Gale, G. R.: Effect of hydroxyurea on incorporation of thymidine into Ehrlich acites tumor cells. Biochem. Pharmacol., 13: 1377 (1964).

14. Hicks, S. P.: Radiation as an experimental tool in mammalian developmental neurology. Physiol. Rev., 38: 337 (1958)

15. Hicks, S. P., and D'Amato, C. J.: Effects of ionising radiation on mammalian development. In: D. H. M. Woolam: Advances in Teratology, Vol. 1, p. 195 (Academic Press, New York, 1966).

16. Klionsky, B., and Wigglesworth, J. S.: Production of experimental models of foetal growth retardation by inhibition of DNA or protein synthesis. Brit. J. Exp. Pathol., 51: 361 (1970)

17. Lyle, J. G., Jonson, K. M., Edwards, M. J., and Penny, R. H.: Effect of prenatal heat stress at mid- and late gestation on the learning of mature guinea pigs. Develop. Psychobiol., 6: 483 (1973).

18. Mohler, W. C.: Cytoxicity of hydroxyurea reversible by pyrimidine deoxyribosides in a mammalian cell line growth in vitro. Cancer Chemother. Rep., 34: 1 (1964).

19. Pfeiffer, S. E., and Tolmach, L. J.: Inhibition of DNA synthesis in HeLa cells by hydroxyurea. Cancer Res., 27: 124 (1967).

20. Rabinovitch, M. S., and Rosvold, H. E.: A closed-field intelligence test for rats. Can. J. Psychol., 5: 122 (1951).

21. Scott, W. J., Ritter, E. J., and Wilson, J. G.: DNA synthesis inhibition and cell death associated with hydroxyurea teratogenesis in rat embryos. Develop. Biol., 26: 306 (1971).

22. Searle, A. G.: Comparative Genetics of Coat Colour in Mammals, p. 40 (Academic Press, New York, 1968).

23. Young, C. W., and Hodas, S.: Hydroxyurea: Inhibitory effect on DNA metabolism. Science, 146: 172 (1964).

24. Young, C. W., Schochetman, G., Hodas, S., and Balis, M. E. Inhibition of DNA synthesis by hydroxyurea: structure-activity relationships. Cancer Res., 27: 535 (1967).

25. Zamenhof, S., Bursztyn, H., Rich, K., and Zamenhof, P. J.: The determination of deoxyribonucleic acid and of cell number in brain. J. Neurochem., 11: 505 (1964).

26. Sigma Chemical Co., Ltd., Kingston-upon-Thames, Surrey, U. K.

27. This research was supported by grants from the Medical Research Council and the National Fund for Research in to Crippling Diseases. We also thank our colleague Dr. J. L. Smart for his invaluable help.

28. Requests for reprints should be addressed to: J. Dobbing, Department of Child Health, University of Manchester, The Medical School, Stopford Building, Oxford Rd., Manchester M13 9PT (UK).

29. Accepted for publication November 12, 1974. 